\title{
Analysis on Employment Status of College Graduates during the COVID-19 Pandemic
}

\author{
Xuran Liu ${ }^{1, *}$ \\ ${ }^{1}$ Digital Economy, King's College London, London, England \\ *Corresponding author email: K21039461@kcl.ac.uk
}

\begin{abstract}
Under the influence of COVID-19, college graduates face severe employment problems, mainly reflected in the internal environment and external situation. At the same time, the Internet has led to the emergence of new employment models. This paper mainly analyzes problems graduates are faced with and employment modes through the college graduates' employment trends under the outbreak. The paper finally concludes that strengthening the construction of employment platforms, providing all aspects of recruitment information, and appropriately extending choosing time can promote the employment of university graduates, hoping these measures can bring some guidance for seniors.
\end{abstract}

Keywords: COVID-19; College graduates; employment modes; employment measures

\section{INTRODUCTION}

Since January 2020, the Novel Coronavirus pandemic has gripped the world. Affected by the epidemic, graduates face many uncertain and unstable factors in employment. In the report on the work of the government for 2020, the most frequently used word is "employment." The report calls for making every effort to stabilize and expand employment and implementing the working framework of ensuring stability, employment, and social security. Although it is now in the post-2021 epidemic period, employment is still the only overlapping and top priority of the "six Stable" and "six Guaranteed" key work. Based on this, it is of great academic value and practical significance to analyze the overall situation and trend of employment of college graduates under the epidemic situation to find the problems faced by college graduates, explore the new mode of employment of college graduates under the epidemic situation and finally put forward policies and measures to promote employment.

COVID-19 has created a grim employment situation. Cai (2020) pointed out that the epidemic has a negative impact on the quantity and quality of employment in China [1]. Li et al. (2020) believe that the subjective factors of unemployed graduates and the objective epidemic situation jointly exacerbate the difficulty of employment, and the problems of unemployed rural graduates seeking jobs need to be solved urgently. Further, the researchers proposed measures [2]. Lian
(2020) believes that the government should change the concept of employment promotion, strive to do a good job in employment services, and encourage new and flexible employment [3]. Zhang, Liu and Mao (2020) believe that colleges and universities should learn about enterprises and public institutions' employment and recruitment information from various aspects and channels and provide timely feedback to students [4]. Cai (2020) believes that the new "Internet + employment" model should be vigorously advocated, enterprises should be encouraged to cooperate with online recruitment platforms, and the time for choosing a job should be appropriately extended.

By reading the existing literature, it is found that previous scholars put forward measures to promote employees based on the problems faced by graduates. This paper focuses on observing the employment trend of college graduates in 2021, analyzes the problems face and the employment model of college graduates, and finally summarizes the measures to promote employment.

\section{EMPLOYMENT TREND OF COLLEGE GRADUATES IN 2021}

\subsection{More than $60 \%$ of college graduates from first-tier and new first-tier cities found jobs locally}

According to data from Boss Zhipin Research Institute, in 2021, the proportion of college graduates 
from first-tier cities and new first-tier cities who want to develop in their cities is more than $60 \%$, indicating that cities have enough talent attraction [5]. However, the proportion of college graduates trained in the third, fourth and fifth-tier cities willing to stay in the city is generally not high, indicating that the city's higher education to adapt to the job scale and talent attraction is obviously insufficient.

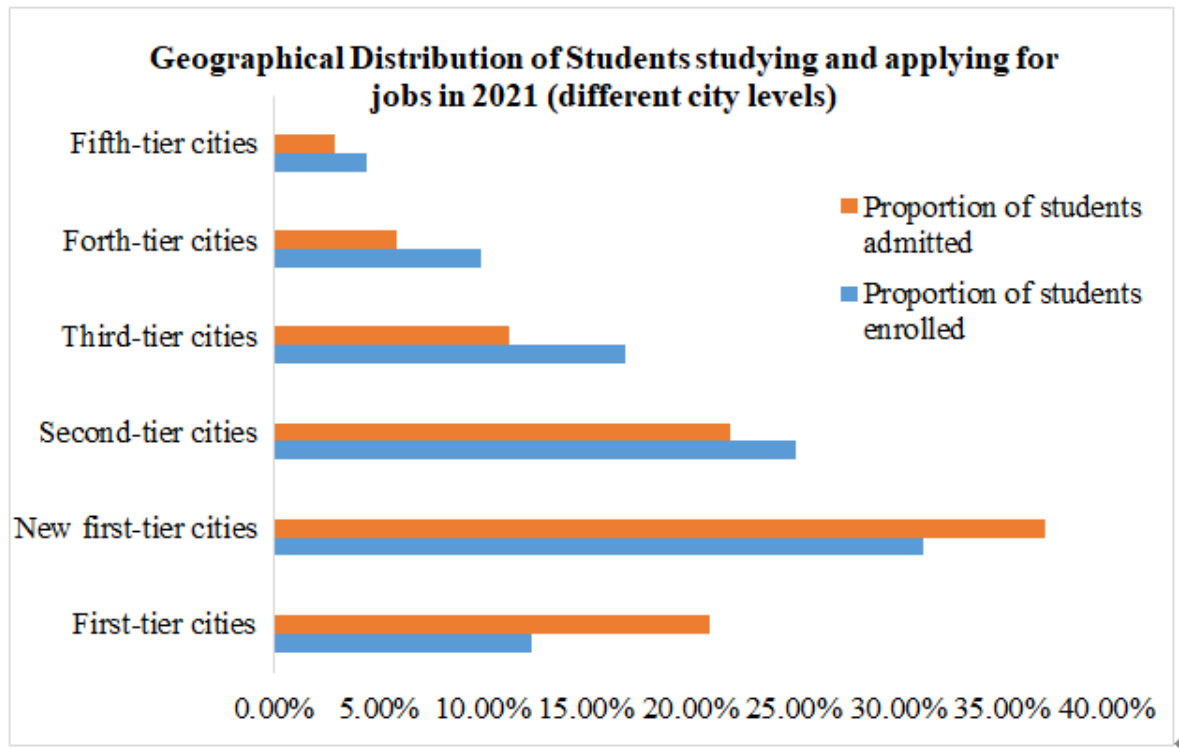

Figure 1. Geographical distribution of 2021 graduates' study and job hunting

First-tier and new first-tier cities retain and attract far more graduates than they produce. Although the talent attraction of new first-tier cities is rapidly increasing, first-tier cities are still the first choice for graduates from highly educated universities. In the spring enrollment season of 2021, among the graduates from other cities seeking jobs in first-tier cities, the proportion of those with a bachelor's degree or above is as high as 63 percent, and those who graduated from "double first-class" universities account for 14 percent, both significantly higher than the overall proportion. This shows that graduates from highly educated universities tend to move to big cities compared with students from other universities.
In 2021, Shenzhen, Shanghai and Chongqing were the three cities with the highest local college graduates retention rate. Shenzhen, Foshan and Suzhou lack local higher education resources, but they are highly attractive to urban talents. They are the three cities that attract the highest proportion of graduates from other cities. This shows that talent attraction not only depends on educational resources but also on the development of other aspects of the city. It should be noted that the Retention rate of fresh graduates is equal to the ratio of scale of fresh graduates from local universities to the scale of fresh graduates looking to find jobs locally

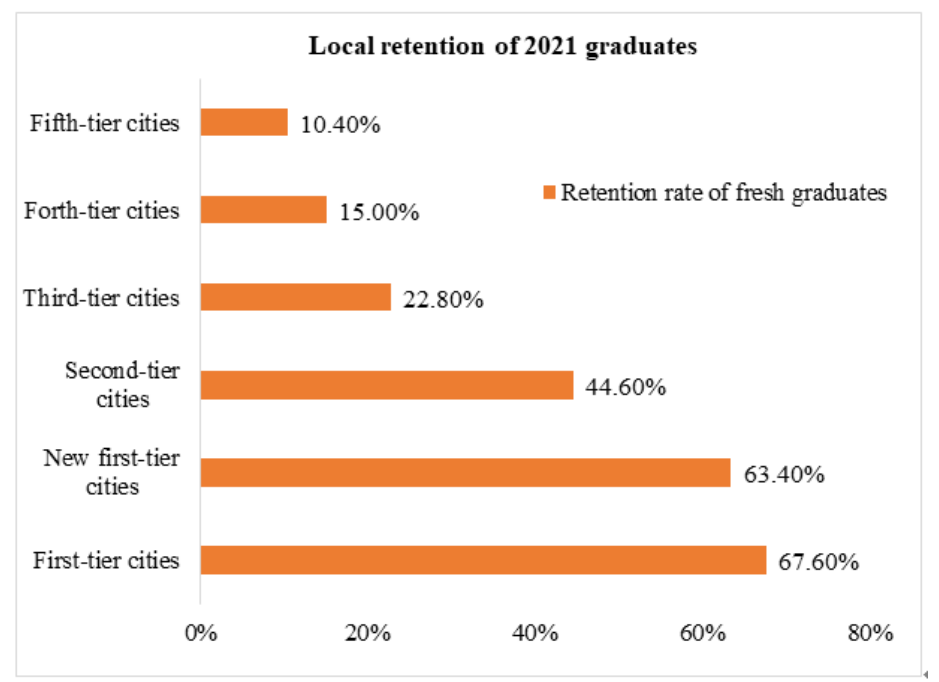

Figure 2. Local retention of 2021 graduates 


\subsection{The private undergraduate graduates live in the clear city development will, but the job competition is not enough}

As shown from Figure 3, graduates of private undergraduate colleges have a relatively clear intention to develop in big cities. According to BOSS Zhipin Research Institute, in 2021, 56 percent of private college graduates will be willing to stay and work in their hometown. New first-tier cities account for the highest proportion of students who are not willing to seek jobs in their host cities, accounting for 32 percent, followed by first-tier cities, accounting for 26 percent. Similarly, both first-tier and new first-tier cities are where the school is located, and more than $60 \%$ of graduates are willing to stay and work there.

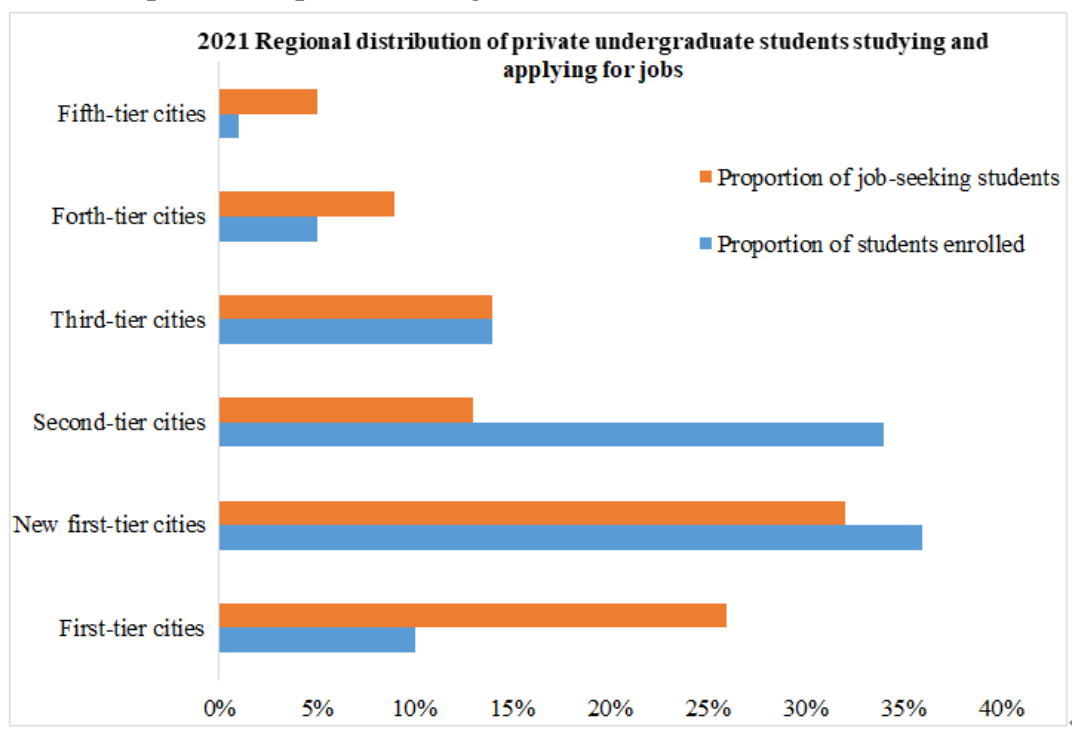

Figure 3. Geographical distribution of 2021 private undergraduate students studying and applying for jobs

However, there are always many challenges for graduates from private universities to find jobs. In the spring recruitment season of 2021, they expect an average salary of 5,270 yuan, far lower than the 6,739 yuan expected by graduates from public universities, and there is a 30-40 percent gap in job competitiveness. Lack of compound skills and job-hunting skills, and lack of practical experience are the main shortcomings of students in private undergraduate colleges, and the positions they choose are mainly basic positions such as course sales, administration, operation and customer service. This shows that private undergraduates still have shortcomings in some respects, and they should constantly improve their abilities. If necessary, they can consider further study or go to other cities for development.

\subsection{The talent demand for the aging industry is concentrated in the new first-tier cities, and there is a structural mismatch between supply and demand}

China's population aged 60 and above accounts for $18.7 \%$ of the total population, with those aged 65 and above accounting for $13.5 \%$, according to the results of the seventh national census, ushering in a new round of accelerated aging. The increasing consumption demand of the elderly has put forward higher requirements for the diversification, high-end and specialization of the elderly industry and also posed a challenge to the talent reserve of the elderly industry.

From January to May of 2021, the recruitment scale of new graduates for positions related to the pension industry increased by $51 \%$ year on year. However, compared with the hot degree of social recruitment, the industry is not willing to recruit new graduates, and the salary competitiveness is not high. In the pension industry, the demand for graduates focuses on the basic positions with low threshold, and the sales, administrative and operation positions account for $64 \%$ of the demand for graduates, but the graduates who are willing to engage in sales positions pay less attention to the pension industry.

On the other hand, the core professional positions in the pension industry are more likely to be recruited by society, and graduates who are willing to enter the industry have insufficient career opportunities. For positions highly related to geriatric medical service and smart old-age product $\mathrm{r} \& \mathrm{~d}$, such as medical and health care, digital technology and product $R \& D$ and design, enterprises have obvious social recruitment preferences. Data from BOSS Zhipin Research Institute show that professional jobs only account for $12 \%$ of the demand of graduates in the pension industry, while they account for $23 \%$ of the overall demand of the industry, showing obvious structural differences.

In the spring recruitment season of 2021 , the number of graduates who intend to find jobs in the aging industry 
has increased $69 \%$ year-on-year, and the average expected salary is 5,889 yuan, up 5\% year-on-year. At present, the recruitment requirements of the pension industry focus on a college degree, and high-end positions tend to be social recruitment. However, $60 \%$ of the prospective graduates have a bachelor's degree and have higher expectations for positions and job content, forming a structural mismatch between supply and demand.

At present, new first-tier cities are the main recruitment areas for pension industry enterprises, especially large enterprises. The more comfortable living environment in new first-tier cities compared with first- tier cities and the dividends brought by rapid economic development are the advantages of the development of pension communities, pension real estate, pension financial services, and other key sectors. The current job demand in first-tier cities is concentrated on the Internet/IT field, focusing on the asset-light and highvalue-added old-age technology field. In second-tier and third-tier cities, the demand for small and medium-sized enterprises with less than 500 employees continues to expand, but the demand is still far less than that of firsttier cities and new first-tier cities. The demand for graduates from the aging industry is mainly concentrated in the new first-tier and first-tier cities, but the demand is stronger in first-tier cities.

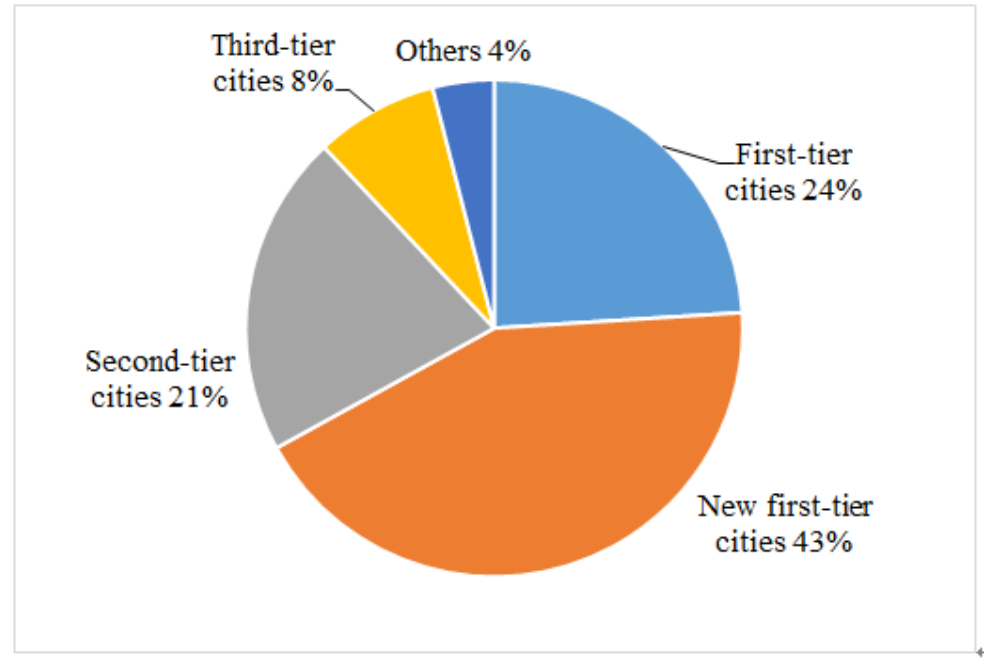

Figure 4. Recruitment demand distribution of graduates in aging industries

\subsection{The scale of fresh graduates who pay attention to the new infrastructure represents a year-on-year increase of $70 \%$, and medium- sized enterprises are developing rapidly}

Typical new infrastructure areas include $5 \mathrm{G}$, big data, cloud computing, artificial intelligence, new energy vehicles and autonomous driving. Data from BOSS Zhipin Research Institute show that in the spring recruitment season of 2021, the recruitment demand of new graduates in the representative field of new infrastructure increased by $57.6 \%$ year on year, and the average recruitment salary increased by $9.2 \%$ year on year to 8,393 yuan, which is $37.3 \%$ higher than the overall average recruitment salary of new graduates.

This shows that the new infrastructure sector has become a hot spot for fresh graduates, especially science and engineering backgrounds. In the new infrastructure sector, medium-sized enterprises with 100-499 employees saw a surge in demand for new graduates, up $69 \%$ year-on-year, with an average salary increase of $13 \%$. The change in demand structure reflects the rapid development trend of mid-sized enterprises in the representative fields of new infrastructure. More companies providing cutting-edge technology and professional solutions are emerging in the middle and lower reaches of the industrial chain, providing good opportunities for graduates interested in this field.

\section{THE PROBLEM THAT UNIVERSITY GRADUATE EMPLOYMENT FACES}

Through the analysis of the employment situation and trend of college graduates under the epidemic situation, it is found that 2021 graduates may face the following problems.

\subsection{External economic pressures continue to mount}

The sudden outbreak of the epidemic has brought even greater challenges to the smooth operation of the economy. General Secretary Xi Jinping believes that the epidemic has a lasting impact on economic operation, mainly reflected in the pressure on industrial enterprises, especially SMEs, which face difficulties in production and operation while increasing the pressure on stable employment [6]. The negative factors of the economic situation have an impact on "stable employment". 


\subsection{Employment and work patterns have changed dramatically}

Due to the needs of epidemic prevention and control, all employment activities, including spring campus recruitment activities and employment guidance and assistance, can only be carried out through online platforms, requiring timely adjustment by universities, students and employers to reduce the impact of the epidemic on graduates' job hunting. It is expected that college graduates in 2021 will face a more complicated and severe employment situation under the combined effects of the economic situation, the scale of graduates and epidemic prevention and control.

\subsection{College employment is still under pressure}

In recent years, with the continuous development of information technology, the function of the employment information systems has been enhanced. However, affected by the epidemic, college employment is still facing unprecedented pressure. There are three main issues to consider.

Firstly, the function of the employment information system is not perfect, and the preventive construction is insufficient. Before the epidemic outbreak, employment in colleges and universities mainly relied on offline channels, with online platforms as supplements. After the epidemic outbreak, graduates could not return to school due to the prevention and control requirements, and all offline employment work, including employment guidance, was carried out online. At this time, the problem of the lack of an employment information system was suddenly exposed. Many colleges and universities rushed to respond and urgently improved the functional modules of the online platform to ensure the development of online employment.

Secondly, the tracking and mastering of graduates' job-hunting trends have become complicated. During the epidemic prevention and control period, in addition to the employment information platforms of universities themselves, third-party online recruitment platforms such as Zhaopin.com and 51JOB have also stepped in. The school will no longer grasp the progress of graduates' job hunting through on-site participation of students or a single platform and timely carry out employment assistance and guidance.

Thirdly, some colleges and universities are not timely enough to help graduates cope with the changing situation. The epidemic has led to an emergency change in the form of spring recruitment, which requires universities to carry out such work as electronic resume making quickly, online application for job hunting, remote interview counseling and so on to help graduates adapt to the change in the way of job hunting and reduce the difficulty for graduates to find a job.

\subsection{Personal anxiety, work and school blocked due to the epidemic}

The graduate groups mainly have the following points that need to cause attention: first, unemployed graduates in certain anxiety. Many reasons result in anxiety, such as the change of spring recruitment and the postponement of the graduation project. In addition, during the epidemic prevention and control period, graduates' internship before employment is restricted, which affects the internship assessment of graduates and affects the normal entry of graduates. In addition, groups of different educational levels have their outstanding problems. For undergraduates, those most affected are those who are uncertain about the outcome of the entrance exam. For graduate students, the biggest impact is mainly for graduate students who need to carry out experimental scientific research to complete their graduate projects. The laboratory closure caused by epidemic prevention and control stopped the subject experiments, and the graduation time could not be determined, or the graduation had to be postponed [7]. The anxiety caused by isolation and control during the epidemic prevention and control period is quite prominent among graduates from Hubei province, which requires the active attention of the university to ensure the smooth employment of students and avoid crisis events. Second, graduates are not actively seeking jobs. Due to the epidemic's impact, the examination results and reexamination arrangements for undergraduates were later than in previous years, and the recruitment of civil servants was also delayed [8]. This leads to some students being at a loss, cannot actively into the spring recruitment. The difficult situation of spring recruitment also makes the graduates who originally hesitated to take the second postgraduate entrance examination more determined to take the second postgraduate entrance examination, resulting in the phenomenon of "slow employment" more prominent; Third, graduates' employment expectations are too high.

\section{THE EMPLOYMENT MODE OF COLLEGE GRADUATES SHOULD BE ADJUSTED}

Due to the employment trend mentioned above and the problems college graduates face under the epidemic, this paper continues to discuss several employment modes for college graduates, including normal recruitment by enterprises, government and social departments, online employment and self-employment. 


\subsection{Conventional enterprise, government, social sector recruitment characteristics}

\subsubsection{Small and medium-sized enterprises have become the focus of attention}

According to Boss Zhipin Research Institute, in the spring recruitment season of 2021, as the economy gradually recovers, the recruitment of new graduates by companies of all sizes increased by more than 40 percent year-on-year. The demand for graduates of large enterprises with more than 10,000 people increased by $59.6 \%$ year on year.

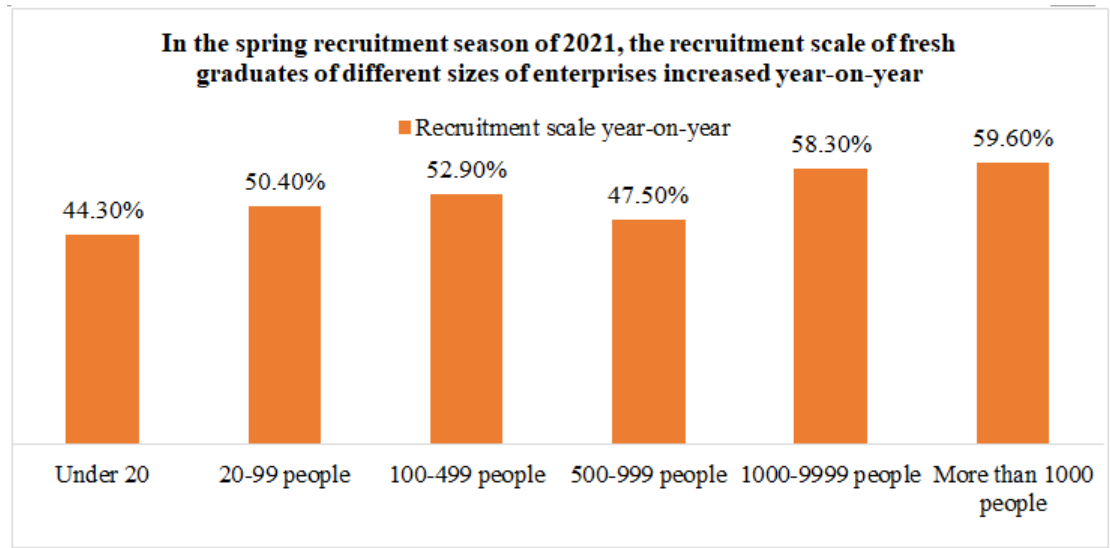

Figure 5. The year-on-year growth of recruitment scale of fresh graduates of different scale enterprises in spring recruitment season 2021

Since 2019, the proportion of recruitment demand for fresh graduates from SMEs with less than 500 employees has declined slightly in terms of demand structure. The epidemic has a greater impact on SMEs, while human costs account for a large proportion of SMEs' operating costs. Therefore, college graduates and small and medium-sized enterprises as the "stable employment" in the market at both ends of the key groups need to continue paying attention.

Therefore, it can be seen that the impact of the epidemic on large enterprises recovered relatively quickly, while small and medium-sized enterprises need to recover their development with the help of all parties to promote the employment of fresh graduates.

\subsubsection{New energy, public administration and community-level employment rose}

In the spring recruitment season of 2021, the job distribution of fresh graduates in the job market shows obvious diversification characteristics. Though the Internet, such as the financial industry, is still a traditional "post", it can be seen that in new energy vehicles, intelligent driving, carbon neutral, carbon up to the peak, rural revitalization, wisdom, agriculture, and a series of industrial policy and the hotspot of new energy/environmental protection, agriculture, forestry and fishing, community management, and other "unpopular" very long for, for highly educated youth talent recruitment scale peaking, there is a doubling of growth in general. This has brought new opportunities to college graduates amid the pandemic.

The year 2021 will be the starting year for comprehensively promoting rural vitalization. According to BOSS Zhipin Research Institute, the demand for new graduates' jobs in agriculture, forestry, animal husbandry and fisheries has doubled, with the number of jobs represented by smart agriculture, modern breeding and agricultural product marketing increasing $135 \%$ year-onyear. Of particular concern is that the demand for college graduates in the first half of 2021 increased by more than $40 \%$ in 52 implements that were finally lifted out of poverty in 2020 , and the production of agricultural and sideline products and brand marketing using electric mill channels became key recruitment fields. 


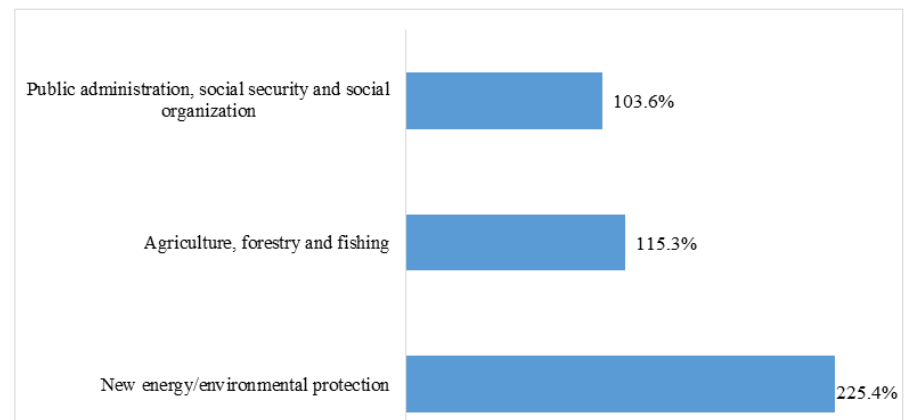

Figure 6. Three industries with the fastest year-on-year growth in the recruitment scale of fresh graduates in the spring recruitment season of 2021

In recent years, the state has actively guided college graduates to seek employment at the grassroots level. To promote high-quality development at the grassroots level. According to a survey conducted by BOSS Zhipin, $45 \%$ of graduates who have not yet decided their jobs are willing to consider grassroots and community positions and hope to get more clear and explicit information channels. This illustrates the effectiveness of the policy and bodes well for the future of rapid development at the grassroots level.

\subsection{Characteristics of Online Employment}

\subsubsection{The number of college students in} intelligent manufacturing is more than half, but it is losing and in urgent need of structural reform

Intelligent manufacturing is the main direction of the manufacturing power strategy. In recent years, there has been a shortage of talents in the field of intelligent manufacturing. As the core talent training base of the manufacturing industry, higher vocational education has attracted wide attention. At present, China has more than 150 higher vocational majors related to intelligent manufacturing, such as industrial robot technology and intelligent control technology.

College graduates account for 54 percent of the 2021 graduates seeking jobs in intelligent manufacturing, and more than a third of them are looking for new first-tier cities. Nearly $60 \%$ of the students who majored in computer science graduated, mainly in computer application technology, computer network technology and other majors. In addition, automation professional job seekers, electromechanical integration technology and electrical automation technology major also occupy a high proportion.

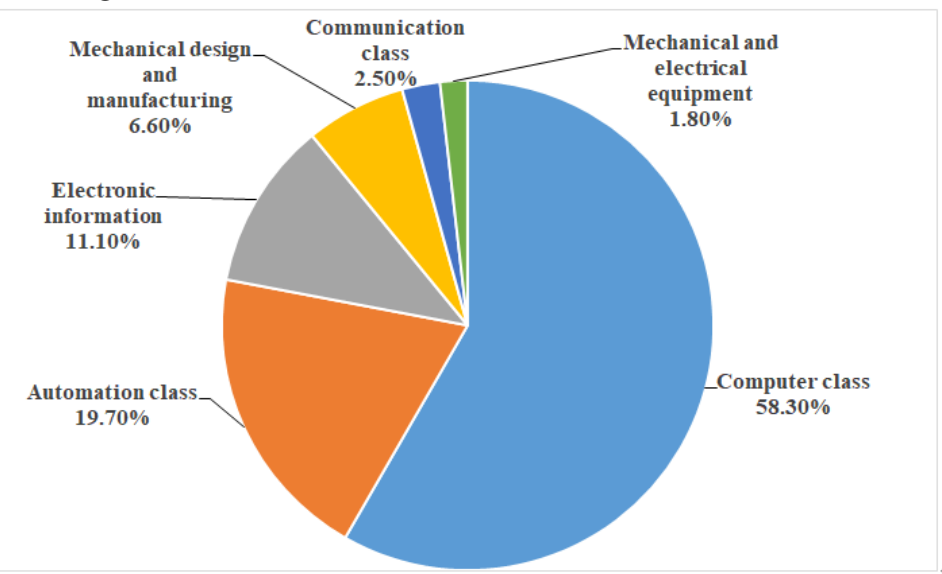

Figure 7. Background distribution of college graduates applying for jobs in intelligent manufacturing in 2021

In 2021 , only about $43 \%$ of college graduates majoring in intelligent manufacturing expect to be engaged in core positions of technology research and development, design, production and manufacturing in relevant enterprises, with an average expected salary of 5,980 yuan. More than $50 \%$ of the graduates expect to enter other industries or non-major related occupations, and majors are brain drain. This situation is caused by students' subjective will and is related to the market recruitment structure.

In addition, data from BOSS Zhipin Research Institute shows that in the spring recruitment season of 2021, only 
$40 \%$ of the positions for fresh graduates in intelligent manufacturing will explicitly recruit college graduates. In the core positions of technology research and development, $70 \%$ of the positions require a bachelor's degree or above. There is a large gap between enterprises requirements and the current graduate supply situation, which has become one of the main manifestations of talent mismatch in the industry.

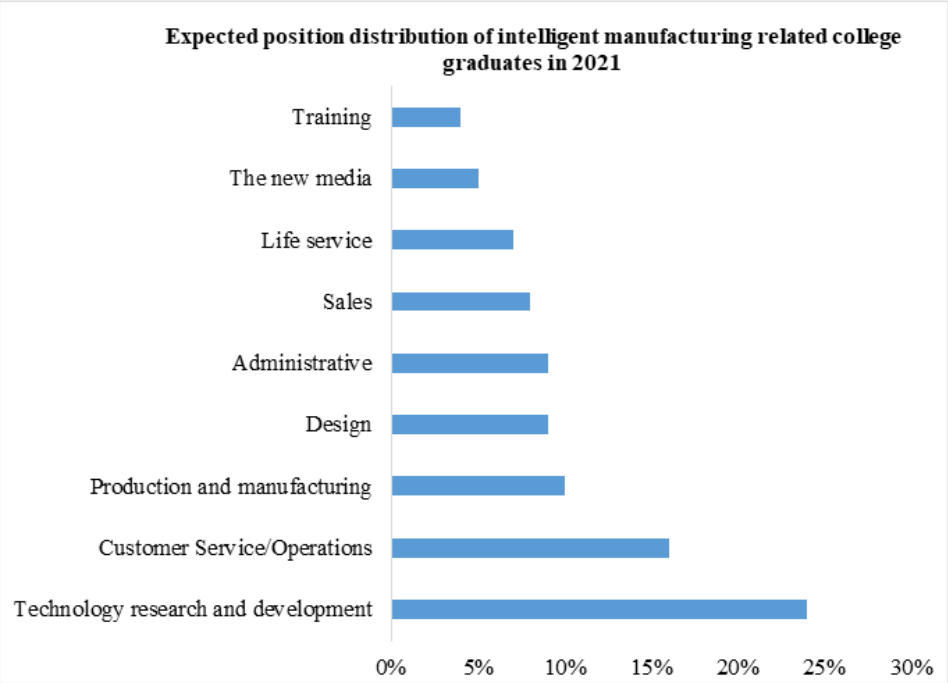

Figure 8 Expected position distribution of college graduates majoring in intelligent manufacturing in 2021

Therefore, the talent demand in intelligent manufacturing is growing rapidly, and the talent supply structure and training mode need to be optimized and reformed urgently. Accelerating the construction of a multi-level talent training system, highlighting the teaching and practice characteristics of different educational levels, and paying more attention to the training of students' learning ability and basic literacy based on professional teaching are all important means to improve the current situation of talent supply.

\subsubsection{Application of cloud technology}

According to data from Boss Zhipin Research Institute, the top five industry categories attracting the most attention from new graduates in the 2021 spring recruitment season are modern service fields, with Internet, electronics/communication and science and technology service industries dominated by digital technology positions, attracting 26.7 percent of new graduates. This shows that network employment is a new popular employment mode.

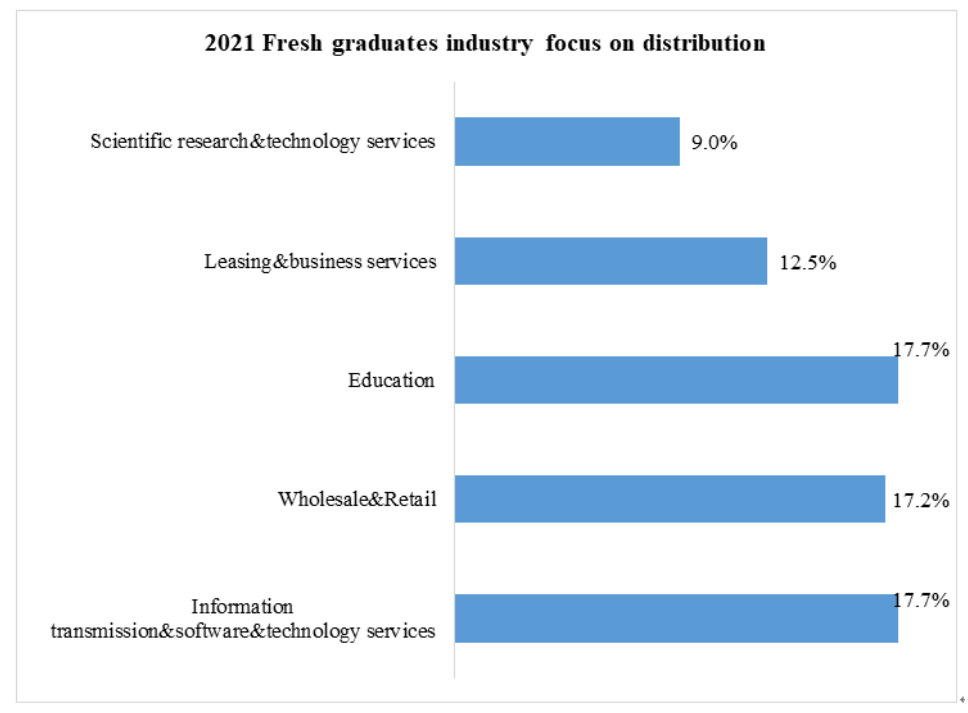

Figure 9. Industry concern distribution of 2021 fresh graduates

Therefore, using cloud technology to build an employment service system for college graduates in the epidemic era is the demand of college students for employment service in colleges and universities.
Colleges and universities use cloud software and virtualization technology to build a software service platform for students' employment, improve the current way of obtaining and using software, solve graduates' job- 
hunting problems and accurately recommend employment positions [9]. Cloud technology is the most effective tool and means to achieve accurate employment of college graduates in the epidemic era, and it is a realistic choice to promote more graduates to implement their jobs as soon as possible and achieve accurate employment of graduates.

To achieve accurate employment means to match automatically and real-time push employment and related service information for individuals according to their jobseeking intentions on the functional platform to realize the full informatization of job seekers' employment management and employment services. Using cloud technology to implement precise graduates' employment is a way for enterprises and graduates to conduct doubleselection in the air through the production of live broadcast, post-broadcast video and subsequent circular push, which has huge advantages that traditional doubleselection cannot have.

In the epidemic era, the traditional job-hunting mode cannot adapt to the current situation of employment. In the job-hunting process of college graduates, cloud technology and other new methods have become the best choice for both graduates and employers in the epidemic era. The application of cloud technology has brought new ideas and methods to college students' employment in the epidemic era. On the one hand, as a tool in the epidemic era, cloud recruitment can run through the entire recruitment process, such as interviews, written tests and entry, increasing the choice opportunities and channels for supply and demand and improving efficiency. On the other hand, as a technical tool and method, cloud technology pays more attention to the correlation between graduates and enterprises, and graduates urgently need this method to seek employment in the epidemic era. Using a network broadcast, supply and demand parties can meet in the cloud and make the double selection in the air, which helps graduates intuitively understand the enterprise culture and employment philosophy, helps students make a better job-hunting plan and provides solid backup candidates for the resumption of work and production and sustainable development of enterprises.

\subsubsection{The advantages of using Internet employment to implement precision employment}

Cloud technology brings new opportunities for college students to achieve precise employment. First of all, an online live broadcast is a good opportunity for both universities and employers to establish long-term cooperative relations. It allows fresh graduates to understand the enterprise better, and for the enterprise itself, it is an opportunity to establish a corporate image and attract outstanding graduates. Secondly, in the live broadcast, graduates can ask questions about salary, position and development opportunities to department managers and hr. directors of enterprises online in real time and get answers online. At the same time, they can intuitively understand the company's internal situation and get familiar with the company environment, company culture, and business in advance. However, it is difficult for graduates to directly enter the company to understand the internal situation of offline recruitment. During the live broadcast activities, the university can also actively answer questions and provide sufficient job-hunting information for graduates to fully meet their job-hunting needs. Employers and students can finally sign employment contracts or achieve internship or employment intentions through cloud interconnection and interaction.

In short, compared with the traditional job-hunting mode, it is a great advantage to realize the cloud-based situational job hunting through online live broadcast. At the same time, the school can also make video production, additional follow-up publicity so that more students participate in the recruitment activities.

\subsubsection{Characteristics of entrepreneurship and employment}

As far as college graduates are concerned, everyone has different ideas about starting a business. Some people enjoy the unique spirit of entrepreneurship, some look forward to the progress and development of entrepreneurship, and some are eager to realize themselves through entrepreneurship. According to statistics, the number of college graduates in 2018, 2019 and 2020 reached 8.21 million, 8.34 million and 8.74 million, respectively. In 2021, the number of college graduates across the country exceeded 9 million for the first time, reaching 9.09 million, an increase of 350,000 year-on-year and another record high. Due to the impact of COVID-19, a certain proportion of college graduates will still be unemployed in 2020, and 9.09 million students will have graduated in 2021, which will further intensify the competition and make it more difficult for graduates to find jobs. In the face of such a severe employment situation, innovation and entrepreneurship may become important options for college graduates in the future. 


\section{Number of college graduates in China \\ - Number of graduates/ten thousand}

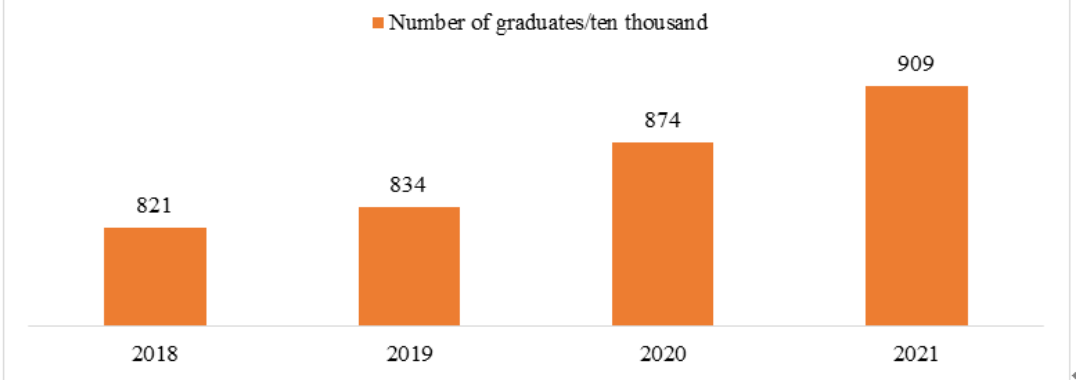

Figure 10 Number of college graduates nationwide

Teachers have become "anchors" during the epidemic, and the diversified development of economic forms has brought prosperity to several emerging professions. So, the online economy will have unlimited imagination in the future, such as red network anchor and electioneering hand. The idea of thousands of troops competing for one job has become quite unrealistic. The rise of successful entrepreneurs such as Jack Ma and Ren Zhengfei is a model for college students. Starting a business and successfully starting a business is the path to become an entrepreneur. College students pursue selfrealization, long for affirmation, and like to be free and easy. Therefore, choosing innovation and entrepreneurship and becoming entrepreneurs is also a choice and direction for college graduates to find jobs during the epidemic.

\section{CONCLUSION}

Through the employment trend of college graduates under the epidemic situation, the main problems faced by college graduates are analyzed.

For example, the work mode has changed greatly, the university employment information system is not perfect, the university for the change of the situation is not timely, and the graduating students face the anxiety of graduation. And this paper analyzes the characteristics of the adjustment direction of employment mode, including the recruitment characteristics of enterprises, government, social departments, network employment characteristics and entrepreneurial employment characteristics. Therefore, the employment of college graduates can be promoted in the following ways.

Firstly, colleges and universities should strengthen the construction of employment platforms and enhance functional training. Schools should strengthen the construction of employment service platforms, an allaround understanding of enterprises and institutions of employment information, convenient graduates promptly. In addition, the school can organize personnel to establish an alumni service platform, establish an alumni association, alumni mutual assistance can be realized, alumni can also timely release the company's recruitment information. In addition, in the face of a complex employment environment, not all students can meet the employment requirements of enterprises and institutions, which requires the school to give full play to its role, take seminars or open relevant courses to train students.

Secondly, an enterprise employing units can provide recruitment information in all aspects. Job fairs and recruitment information are mostly displayed online, such as WeChat official accounts and QQ. As a result, the information is tedious and incomplete, and students cannot reasonably screen the information they need. Enterprises and institutions shall establish and improve recruitment information networks, timely update and release dynamic information, and add screening conditions to facilitate the selection of graduates. In this way, it is beneficial for the company to recruit suitable candidates and conducive to the effective employment of graduates.

Thirdly, the time for job selection should be appropriately extended. As the epidemic has led to a serious decline in the demand for certain positions, it is advisable to give fresh graduates the qualification to participate in the two-year autumn recruitment, which can, to a certain extent, cope with the rebound in enterprise employment demand after the epidemic.

Future research can follow up the employment trend and the change of employment mode of college graduates and observe whether the current measures to promote employment are still applicable in the future. However, because times are progressing, perhaps employment patterns and measures are also changing. This requires constant updating of data, constant research and analysis.

\section{REFERENCES}

[1] Cai.(2020). Estimation of the impact of the epidemic on the current employment situation in China People's Forum (09),92-94.

[2] Li, Sun, Wu, Shan.(2020). An empirical study on employment status of College graduates in China under the impact of COVID-19. Journal of East China Normal University 38 (10). Doi: 10.16382/j.cnki.1000-5560.2020.10.010 
[3] Lian.(2020). Thinking on strategies to promote employment during the epidemic. Chinese market (36), 184-185. The doi: 10.13939 / j.carol carroll nki ZGSC. 2020.36.184.

[4] Zhang, Liu, Mao. (2020). Explore ways to promote employment in the context of the COVID-19. New Business Weekly,2020 (9):284-286.

[5] Xi. (2020). Speech at the Meeting of the Standing Committee of the Political Bureau of the CPC Central Committee on COVID-19 response. Seeking truth from facts, (4).

[6] Chen.(2020). Thoughts on college students' employment guidance under the situation of fighting against epidemic. Employment of College Students in China (06), 38-42+53.

[7] Zhang. Bian.(2020). Optimization of career guidance courses in colleges and universities in the context of COVID-19. Standardization for the Masses (17), 117-118.

[8] Tian.(2020). Firm belief and Forge ahead -- research on accurate employment of college graduates in the epidemic era. World of Labor Security (15),7+9.

[9] Du. Ren. (2021). Research on college students' employment under the normal prevention and control of COVID-19. Journal of Suzhou Institute of Education (04),33-36. doi:10.13985/j.cnki.34-1227/ C.2021.04.007. 